\title{
The Use of River Sediments for Plant Nursery in the Framework of the LIFE+ project CLEANSED
}

\author{
Luciano Massetti ${ }^{1}$, Francesca Ugolini ${ }^{1}$, Francesco Sabatini ${ }^{1}$, Fabrizio Ungaro ${ }^{1}$, Costanza Calzolari ${ }^{1}$, \\ Stefania Damiano ${ }^{2}$, Francesca Martelli ${ }^{1}$, and Graziana Masciandaro ${ }^{3}$
}

\begin{abstract}
River sediments are an integral and dynamic part of river basins but where human activities interfere with sediment quantity or quality, their management becomes necessary. Dredging and especially stocking polluted sediments is highly expensive, therefore it would be valuable to find ways to make them a reusable product instead of throwing to landfill. On the other side, there are productive field activities demanding high quantity of soil, such as plant nursing. A European estimation calculates that every year plant nursing consumes about $5.2 \cdot 10^{6} \mathrm{~m}^{3}$ of soil. To address these issues, five Institutions from Italy and one from Spain are involved in the CLEANSED project (LIFE12 ENV/IT/00652, 2013-2016). One of the aims of the project is to test the use river sediments as plant growing substrates after being decontaminated through phytoremediation technologies. After phytoremediation process, the sediments are experimented as amendant in soil used for plant nursing: the substrate has to guarantee root development but also soil cohesion of root balls when the plants are extracted for sale. The experimental plan aims to test substrates with different percentage of sediments and alluvial soil in order to identify the mixture which guarantees the best plant quality. From May 2014 to November 2015, three ornamental bush species (Photinia x fraseri var. Red Robin, Viburnum tinus L. and Eleagnus macrophylla $L$.) were planted into woody frames filled with different percentage of sediments and soil (respectively 0 and $100 \%, 33 \%$ and $66 \%$ and $50 \%$ and 50\%). Physical and chemical properties of the substrates as well as plant growth, physiological behavior and stress signals have been monitored through 2014 and 2015 vegetative season. The aim of this study is to present the setting and some results about plant growth, with a focus on the effect of temperature and substrate on the growth of the investigated species.
\end{abstract}

Keywords - air temperature, plant growth, plant nursing, soil.

Luciano Massetti ${ }^{1}$ is with the Institute of Biometeorology of the National Research Council, Firenze, 50145 ITALY

Francesca Ugolini ${ }^{1}$ is with the Institute of Biometeorology of the National Research Council, Firenze, 50145 ITALY

Francesco Sabatini ${ }^{1}$ is with the Institute of Biometeorology of the National Research Council, Firenze, 50145 ITALY

Fabrizio Ungaro ${ }^{1}$ is with the Institute of Biometeorology of the National Research Council, Firenze, 50145 ITALY

Costanza Calzolari ${ }^{1}$ is with the Institute of Biometeorology of the National Research Council, Firenze, 50145 ITALY

Francesca Martelli ${ }^{1}$ is with the Institute of Biometeorology of the National Research Council, Firenze, 50145 ITALY

Stefania Damiano ${ }^{2}$ is with the University of Florence, 50123 Firenze, ITALY

Graziana Masciandaro ${ }^{3}$ is with the Institute of Ecosystem Study of the National Research Council, Pisa, 56124 ITALY

\section{INTRODUCTION}

E VERY year in Europe 130 million $\mathrm{m} 3$ of polluted river $\mathcal{C}_{\text {sediments are dredged and should be disposed in }}$ expensive ways. The need of dredging of hydro ways channels nowadays face the problem of high costs of sediments management. These sediments are special waste due to the high concentration of pollutants like hydrocarbons and heavy metals, and must be treated in a special way, generally accumulated firstly in stocking pools and then transported to the landfill. This method generates an increasing need of landfills and implies high costs of management. So, the perspective of reusing such kind of sediments might be a good option alternative to the landfill. On one side, their nature makes them suitable for agronomic purposes despite the need of decontamination. To achieve this purpose, Agriport methodology has demonstrated its effectiveness in the remediation from pollutants and enables to produce a substrate with fair properties as soil amendant [1], [2]. On the other side, plant nursing faces great soil consumption: in open field productions when plants are extracted for sale and in pots or other production systems, with consequent need of refilling. In fact every year 5.2 million $\mathrm{m}^{3}$ of ground soil removed for plant nursing activities. The CLEANSED project, funded under the LIFE+ programme, aims to demonstrate that polluted river sediments can be treated and reused in two different productive sectors in an ecologically and financially sustainable and advantageous way. One sector of application is plant nursing and the aim of this action is to demonstrate that the decontaminated river sediments might be used as soil amendments in plant nursing, especially in open field productions. Three bush species planted in wood frames, filled with different mixture of soil and sediments, parameters were monitored during 2014 and 2015 to assess several physiological, chemical and physical response. The aim of this study is to present data about plant growth monitoring of these plant species cultivated in three different mixture of agronomic soil and decontaminated river sediments and analyze the relationship with air temperature and soil type. Several studies assessed that air temperature is the main meteo-climatic driver of plant phenology [3], [4] and plant growth [5] also in an urban environment due to the increase of urbanization [6], [7]. Several simulation models for plant phenology and plant 
growth are based on the so called GDD. These models, called "thermal time models", assume that the growth stage of plants is proportional to the temperature forcing calculated as the sum of temperature exceeding a fixed threshold [8], [9].

\section{MATERIALS AND METHODS}

The experimental field was set up at Centro Sperimentale per il Vivaismo (Ce.Spe.Vi.) that is a no profit organisation in Pistoia - Italy, aiming to support experimental research in plant nursing. The experimental plan aimed to test the use of decontaminated river sediments (DS) mixed with agronomic soil (AS) in the open field nursing production. The experimental field was set up in April 2014 using $5 \mathrm{~m}^{3}$ of decontaminated river sediments and $13 \mathrm{~m}^{3}$ of agronomic soil. Two mixed substrates of DS and AS (T33 with DS at 33\% and T50 with DS at 50\%) were compared to a control of $100 \%$ AS (CTL) to assess best amendment capacity. Two replicas of woody frames for each mixture ( $3 \times 2 \mathrm{~m}$, depth $0.5 \mathrm{~m})$ were used for simulating an open field cultivation in order to assess physiological and growth responses of ornamental plants on these substrates. Three ornamental species were selected on the base of their water needs, in order to see differences in growth according to the soil properties: (Fig. 1):

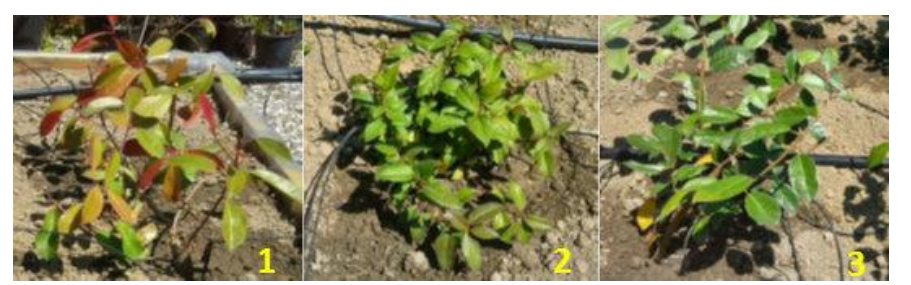

Fig. 1 Ornamental species used for the experiment: 1. Photinia $x$ fraseri var. Red Robin; 2. Viburnum tinus L.; 3. Eleagnus macrophylla L.

- (PHO) Photinia x fraseri var. Red Robin is a Chinese fast growing species and rather exigent in water;

- (VIB) Viburnum tinus L. is a Mediterranean xerophytic species characterised by slow growth;

- (ELE) Eleagnus macrophylla L. is a Japanese species, with water needs in between the two other species and medium rate growth.

A total of 144 one year old plants were transplanted from pot to the experimental field: 48 plants (16 per species) in each woody frame (Fig. 2).

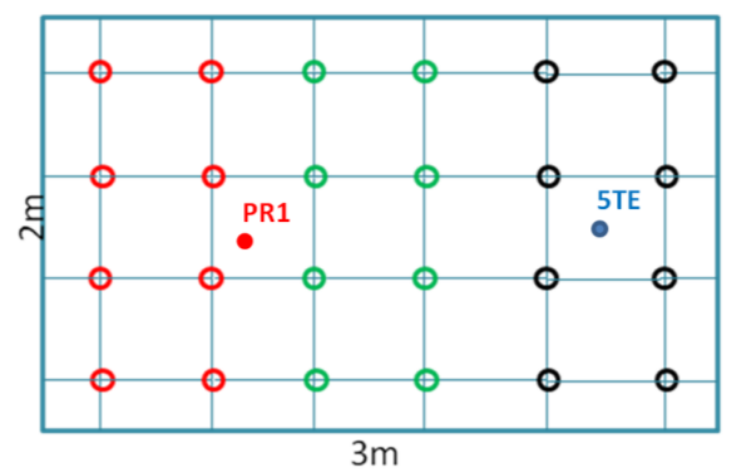

Fig.2 Plant setting inside a woody frame.
Several plant physiological parameters were measured during 2014 in all the individuals. At the end of the first vegetative season, 72 plants were extracted and root ball cohesion and biomass parameters were assessed. Quantitative and qualitative assessment continued in 2015 on the remaining 72 individuals that were pruned at the beginning of the 2015 vegetative season.

Plant growth was measured by the length of the main branch (cm). Measurements were taken twice in 2014 (mid June and end of vegetative season) and 10 times from March to November 2015. Air temperature data were provided by Cespevi weather station. Relationships between growth data of each species and air temperature indices and soil type was also investigated. In this study we used growing degree days (GDD) as a cumulative index that takes into account the effect of temperature on plant growth. GDD was calculated according the following formula:

$$
G D D=\sum_{k=1}^{\mathrm{n}}(T k-T b) \text { if } \mathrm{T}_{\mathrm{k}}>\mathrm{T}_{\mathrm{b}} \text { else }\left(\mathrm{T}_{\mathrm{k}}-\mathrm{T}_{\mathrm{b}}\right)=0
$$

Where $\mathrm{k}$ day of the year DOY $\left(\mathrm{k}=1,1^{\circ} \mathrm{Jan} ; \mathrm{k}=90,31^{\circ}\right.$ Mar $)$ $\mathrm{T}_{\mathrm{k}}$ average air temperature day $\mathrm{k}, \mathrm{T}_{\mathrm{b}}$ base temperature $=10^{\circ}$ C.

The relationship between growth data and GDD was assessed by linear regression, while the relationship with soil type was assessed by ANOVA and significance level was assessed by $\mathrm{p}$ coefficient lower than 0.05 .

\section{RESULTS}

In 2014, plant growth was significantly different only for ELE (CTL vs T33, p=0.047) in June (Table 1). In 2015 plant growth significant growth difference was assessed only for VIB both in June (CTL vs T33, p<0.001; T33 vs T50, $\mathrm{p}=0.032$; CTL vs T50, $\mathrm{p}<0.001$ ) and November (CTL vs T33, $\mathrm{p}<0.039$; CTL vs T50, $\mathrm{p}<0.031)$. Plants were always higher in 2015 than 2014 because the vegetative period was longer since in 2014 they were planted in May while in 2015 they started growing after pruning in February.

In 2015 PHO and ELE grew at the same speed rate independently from the soil type, while VIB grew significantly quicker in T50 than CTL all along the year (Fig. 3). Growth rate per 100 GDD increase ranged between $4.2 \mathrm{~cm}$ (T50) to $4.6 \mathrm{~cm}$ (T33) for PHO between $7.0 \mathrm{~cm}$ (T33) to $7.5 \mathrm{~cm}$ (CTL for ELE and between $1.7 \mathrm{~cm}$ (CTL) to $2.6 \mathrm{~cm}$ (T50) for VIB.

TABLE I

MEAN HEIGHT AND STANDARD DEVIATION

\begin{tabular}{cccccc}
\hline \hline Species & Mix & $\begin{array}{c}\text { June } \\
2014\end{array}$ & $\begin{array}{c}\text { October } \\
2014\end{array}$ & June 2015 & $\begin{array}{c}\text { November } \\
2015\end{array}$ \\
\hline PHO & CTL & $48.6 \pm 8.8$ & $95.3 \pm 5.3$ & $89.4 \pm 9.7$ & $151.1 \pm 10.4$ \\
& T33 & $51 \pm 7.3$ & $93.8 \pm 5.2$ & $95.3 \pm 10.6$ & $165.4 \pm 23.3$ \\
& T50 & $50.2 \pm 9.5$ & $95.2 \pm 17.3$ & $95.4 \pm 13$ & $156.3 \pm 28.5$ \\
ELE & CTL & $49.6 \pm 5.2$ & $134.2 \pm 30.8$ & $96.4 \pm 8$ & $225.6 \pm 18.6$ \\
& T33 & $42 \pm 5.1$ & $103.8 \pm 12.5$ & $102.6 \pm 10$ & $214.4 \pm 23.6$ \\
& T50 & $44.6 \pm 3.9$ & $113.4 \pm 13.3$ & $93.9 \pm 8$ & $210.1 \pm 18.1$ \\
VIB & CTL & $25.6 \pm 4.3$ & $54.2 \pm 1.9$ & $36.1 \pm 6.5 \mathbf{~ a}$ & $63.6 \pm 13.8$ a \\
& T33 & $30.6 \pm 4.7$ & $54.9 \pm 1.4$ & $49.9 \pm 4.8 \mathbf{b}$ & $78.6 \pm 4.6 \mathrm{~b}$ \\
& T50 & $26.2 \pm 2.5$ & $55.6 \pm 4$ & $44.9 \pm 3.4 \mathbf{c}$ & $89.1 \pm 5.4 \mathrm{~b}$ \\
\hline \hline
\end{tabular}

Photinia $\mathrm{x}$ fraseri var. Red Robin (PHO), Eleagnus macrophylla L. (ELE) and Viburnum tinus L. (VIB) for 0\% sediments (CTL), 33\% sediments (T33) and 50\% sediments (T50) in 2014 and 2015.. Small letters indicate significant differences between treatment within the same species by ANOVA followed by Bonferroni test at $\mathrm{p}<0.05$. 


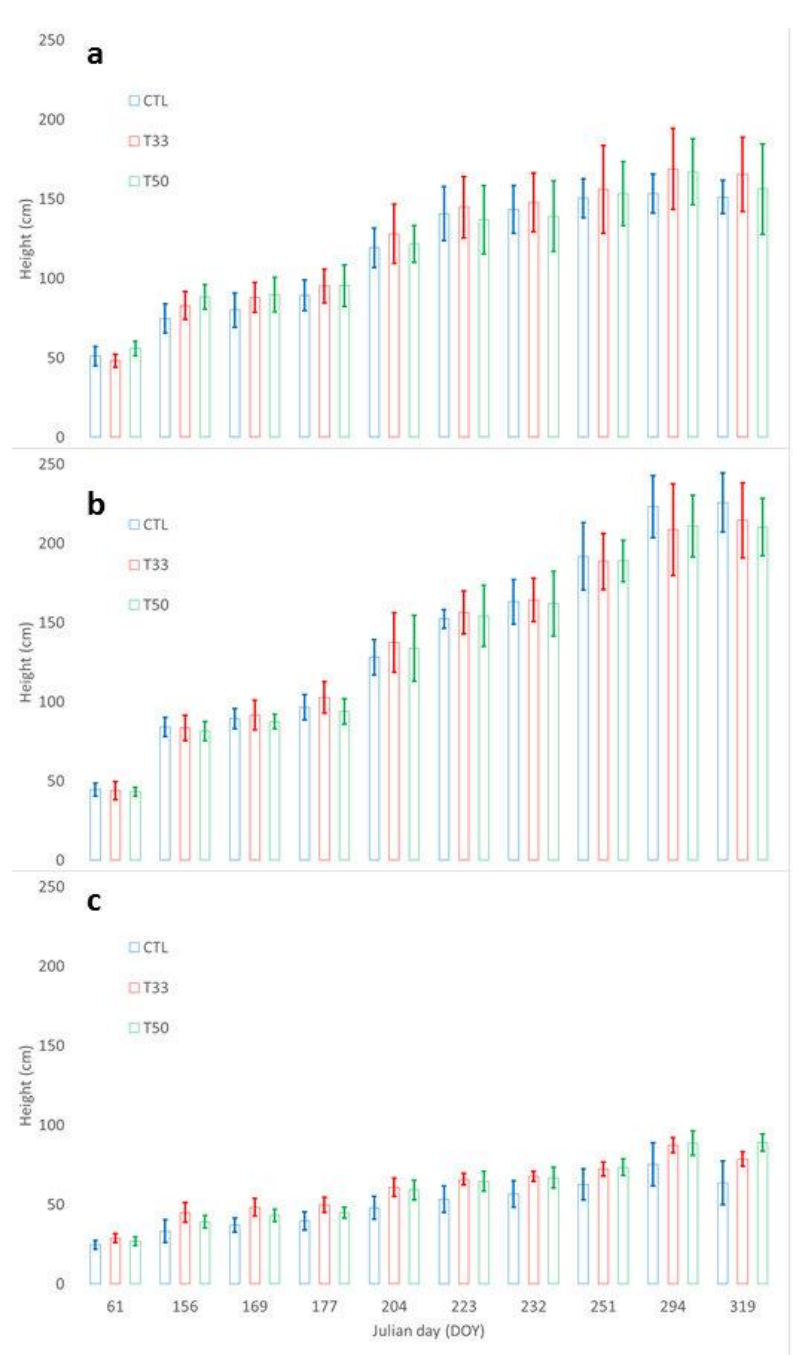

Fig. 3 Mean growth and standard deviation $(\mathrm{cm})$ of Photinia $x$ fraseri var. Red Robin (a), Eleagnus macrophylla L. (b) and Viburnum tinus L. (c) during 2015 vegetative season.

\section{DISCUSSION AND CONCLUSION}

Productive activities such as plant nursing are responsible of a great amount of soil loss, so that soil recovering becomes necessary. Nonetheless, the use of agricultural soil for this purpose would not help to recover it especially if coming from the same basin. In contrast, the use of polluted sediments, properly decontaminated, seem to be an efficient alternative, allowing also to save money otherwise spent for management and stock. This experiment showed that the sediments decontaminated through Agriport (mainly based on phytoremediation) and Cleansed (mainly based on land farming) methodologies can be used in the plant nursery sector. The presence of decontaminated sediments in the soil never affected negatively plant growth of PHO and ELE. On the contrary sediments had a positive effect on VIB growth in 2015. The sediments, improve water infiltration and drainage but also carbon and nitrogen concentration [10], Nevertheless, in the year 2014, the growth of the plants cultivated in substrates with certain percentages of sediments was similar to the growth of those in the agricultural soil (control). This may be due to the fact that plants were transplanted in the new substrates only in May, facing an initial transplant stress and then, an atypical rainy summer (fig. 4), which likely affected root apparatus [11]. On the other hand, summer 2015 was warmer and plants of all species showed marked growth rates. However, only Viburnum tinus L., xerofitic species, showed higher rates in substrates with sediments, as if they matched the species needs.

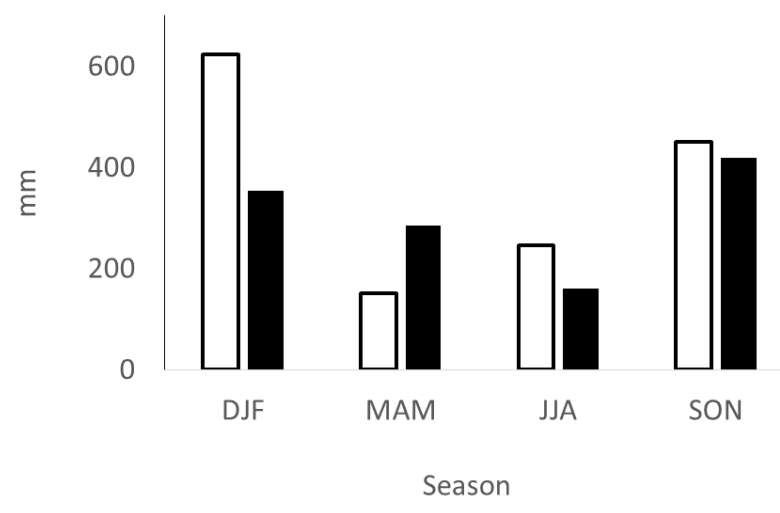

Fig. 4 Seasonal precipitation at Cespevi in 2014 (white box) and in 2015 [black box) .

\section{ACKNOWLEDGMENT}

This study was made in the framework of the CLEANSED project (LIFE12 ENV/IT/00652, 2013-2016).

\section{REFERENCES}

[1] R. Iannelli, V. Bianchi, G. Masciandaro, B. Ceccanti B, A. Pretner, "Agricultural reuse of polluted dredged sediments: the AGRIPORT European Project" in: IWA - XII International Conference of Wetland System for Water Pollution Control (Venezia, 4-7 ottobre 2010). Proceedings, pp. 472 - 479.

[2] S. Doni, C. Macci, E. Peruzzi, R. Iannelli, B. Ceccanti, G. Masciandaro, "Decontamination and functional reclamation of dredged brackish sediments", Biodegradation Vol. 24, pp. 499-512. http://dx.doi.org/10.1007/s10532-012-9606-1

[3] C. Schleip, T.H. Sparks, N. Estrella, A. Menzel, "Spatial variation in onset dates and trends in phenology across Europe", Clim Res, Vol. 39(3), pp. 249-260 (2009). http://dx.doi.org/10.3354/cr00830

[4] F.E. Wielgolaski, "Phenological modifications in plants by various edaphic factors", Int J Biometeorol Vol. 45(4), pp. 196-202 (2001). doi: $10.1007 / \mathrm{s} 004840100100$. http://dx.doi.org/10.1007/s004840100100

[5] R.B. Myneni, C.D. Keeling, C.J. Tucker, G. Asrar, R.R. Nemani, "Increased plant growth in the northern high latitudes from 1981 to 1991" Nature, Vol. 386(6626), pp. 698-702 (1996). doi:10.1038/386698a0. http://dx.doi.org/10.1038/386698a0

[6] L. Massetti, M. Petralli, S. Orlandini, "The effect of urban morphology on Tiliaxeuropaea flowering" Urban Forestry \& Urban Greening Vol. 14(1), pp. 187-193. (2015) doi:10.1016/j.ufug.2014.10.005. http://dx.doi.org/10.1016/j.ufug.2014.10.005

[7] A. Mimet, V. Pellissier, H. Quénol, R. Aguejdad, V. Dubreuil, F. Rozé, "Urbanisation is associated with early flowering: evidence from Platanus acerifolia and Prunus cerasus" Int J Biometeorol Vol. 53, pp. 287-298 (2009). doi: 10.1007/s00484-009-0214-7. http://dx.doi.org/10.1007/s00484-009-0214-7 
[8] H. Hänninen, "Modelling bud dormancy release in trees from cool and temperate regions". Acta For Fenn, Vol. 213, pp. 1-47.

[9] T. Linkosalo, "Mutual regularity of spring phenology of some boreal tree species: predicting with other species and phenological models" Can J For Res Vol. 30 pp. 667- 673 (2000) http://dx.doi.org/10.1139/x99-243

[10] F. Ugolini, C. Calzolari, G.M. Lanini, F. Martelli, L. Massetti, F. Sabatini, F. Ungaro, S. Damiano, G. Masciandaro, "Another future for hydro ways sediments", In: Cossu R., He P., Kjeldsen P., Matsufuji Y., Reinhart D., Stegmann R. (Eds.) Sardinia 2015 15th International Waste Management and Landfill Symposium. Symposium Proceedings. Forte Village_S. Margherita di Pula (CA). Italy. 5-9 October 2015. ISBN 9788862650212. ISSN 2282-0027

[11] F. Ugolini, C. Calzolari, G.M. Lanini, F. Martelli, L. Massetti, F. Sabatini, F. Ungaro, S. Damiano, G. Masciandaro, , "From special waste into products: polluted canal sediments as substrates for plant nursing cultivation", iForest (in review). 